\title{
Ethyl acetate fraction from Angelica sinensis inhibits IL-1 $\beta$-induced rheumatoid synovial fibroblast proliferation and COX-2, PGE2, and MMPs production
}

Won-Seok Lee, Jin-Han Lim, Myung-Soon Sung, Eun-Gyeong Lee, Yoo-Jeong Oh and Wan-Hee Yoo*

\begin{abstract}
Background: The root of Angelica sinensis (AS), also known as "Dang-gui," was a popular herbal medicine widely used in the treatment of gynecological diseases in China, Korea, and Japan for a long time. This study aimed to determine the effects of ethyl acetate fraction from Angelica sinensis (EAAS) on the interleukin-1 $\beta$ (IL-1 $\beta$ )-induced proliferation of rheumatoid arthritis synovial fibroblasts (RASFs), and production of matrix metalloproteinases (MMPs), cyclooxygenase (COX) 2, and prostaglandin E2 (PGE2), involved in articular bone and cartilage destruction, by RASFs.

Results: RASF proliferation was evaluated with cholecystokinin octapeptide (CCK-8) reagent in the presence of IL-1 $\beta$ with/without EAAS. Expression of MMPs, tissue inhibitor of metalloproteinases-1 (TIMP-1), COXs, PGE2, and intracellular mitogen-activated protein kinase (MAPK) signaling molecules, including p-ERK, p-p38, p-JNK, and NF-KB, were examined using immunoblotting or semi-quantitative reverse transcription-polymerase chain reaction and enzyme-linked immunosorbent assay. EAAS inhibited IL-1 $\beta$-induced RASF proliferation; MMP-1, MMP-3, and COX-2 mRNA and protein expressions; and PGE2 production. EAAS also inhibits the phosphorylation of ERK-1/2, p38, and JNK, and activation of NF-KB by IL-1 $\beta$.
\end{abstract}

Conclusion: EAAS might be a new therapeutic modality for rheumatoid arthritis management.

Keywords: Angelica sinensis, COX, IL-1 $\beta$, MMPs, Rheumatoid arthritis (RA)

\section{Background}

Rheumatoid arthritis (RA) is a chronic inflammatory disease characterized by robust infiltration of leukocytes into the synovium, resulting in hyperplasia of the synovial lining, progressive cartilage destruction, and finally, erosion of the underlying bone [1]. Synovial fibroblasts mediate joint destruction in RA by producing inflammatory mediators such as cytokines, matrix metalloproteinases (MMPs), and cyclooxygenase (COX)-2 that facilitate the expansion and invasion of synovial fibroblasts into the adjacent tissue. The regulation of these events has

\footnotetext{
* Correspondence: ywhim@jbnu.ac.kr

Department of Internal Medicine, Division of Rheumatology, Chonbuk National University Medical School and Research Institute of Clinical Medicine of Chonbuk National University Hospital-Chonbuk National University, San 2-20 Geumam-dong, Deokjin-gu, Jeonju, Jeonbuk 561-180, South Korea
}

been a primary target of therapeutic intervention in RA [2]. Interleukin $1 \beta$ (IL-1 $\beta$ ) is considered the most important cytokine in the pathogenic process of inflammation in RA; it induces proliferation of rheumatoid arthritis synovial fibroblasts (RASFs), and production of high levels of MMPs and prostaglandin E2 (PGE2) via COX expression by RASFs [3].

The root of Angelica sinensis (Oliv.) Diels (Apiaceae) (AS), also known as "Dang-gui," was a popular herbal medicine widely used in the treatment of gynecological diseases in China, Korea, and Japan for a long time. Chemical and pharmacological studies of various extracts or compounds obtained from this herb were found to increase myocardial blood flow, reduce radiation damages [4-6]. It was also demonstrated as mainly consisting of polysaccharides and having a protective effect 
on gastrointestinal damage and hepatic injury $[7,8]$. Recently, the ethyl acetate extract of AS (EAAS) showed higher inhibitory activity of NF- $\mathrm{B}$ transactivation than hexane or water fractions [9]. However, no study has investigated the effects of EAAS on inflammatory reactions, including proliferation of RASFs and production of PGE2 by RASFs, which play a crucial role in the pathogenesis of synovitis in RA.

The present study was undertaken to study the effects of EAAS on IL-1 $\beta$-induced production of proinflammatory mediators by RASFs. MMPs, PGE2 and COX-2 were studied and intracellular signaling factors were evaluated to identify the mechanisms of the effects of EAAS. Here we showed that EAAS can inhibit IL-1 $\beta$-induced proliferation and inflammatory reactions via mitogen activated protein kinase (MAPK)/nuclear factor- $k \mathrm{~B}(\mathrm{NF}-\mathrm{kB})$ pathways in RASFs.

\section{Results}

\section{EAAS inhibits IL-1 $\beta$-induced proliferation of RASFs}

To evaluate the effect of EAAS on the growth properties of RASFs, we initially measured cell proliferation with IL- $1 \beta$ for 3 days. IL- $1 \beta$ is well known as a potent growth-promoting factor for RASFs. Cell proliferation was assayed as described in Materials and Methods. As shown in Figure 1a, IL-1 $\beta$ accelerated the proliferation of RASFs dose-dependently (from 0.1 to $10 \mathrm{ng} / \mathrm{mL}$ ) over time. To know the effect of EAAS on IL-1 $\beta$-induced proliferation of RASFs, EAAS $(100 \mu \mathrm{g} / \mathrm{mL})$ was added to the RASFs cultures with/without IL- $1 \beta(1.0 \mathrm{ng} / \mathrm{mL})$ for 2 days, and cholecystokinin octapeptide (CCK-8) assay was performed. As shown in Figure 1b, the increase in RASF proliferation was significantly greater in the culture with IL-1 $\beta$ than that in the control without IL-1 $\beta$ and EAAS $(p<0.05)$. In Figure $1 c$, to ascertain the dosedependent effect of EAAS on IL-1 $\beta$-induced proliferation of RASFs, different doses of EAAS (20, 100, $200 \mu \mathrm{g}$ / $\mathrm{mL}$ ) were added to the RASFs cultures with IL-1 $\beta$ (1.0 ng/mL) for 2 days, and CCK-8 assay was performed.

\section{Effect of EAAS on IL-1 $\beta$-induced MMPs, TIMPs, and COX mRNA expressions in RASFs}

Real-time PCR was performed to evaluate the expressions of MMP-1, MMP-3, Tissue inhibitor of metalloproteinase (TIMP)-1, and TIMP-2 mRNA in the monocultured RASFs. RASFs were stimulated with IL-1 $\beta(1.0 \mathrm{ng} / \mathrm{ml})$ for 48 hours in the presence or absence of EAAS $(100 \mu \mathrm{g} / \mathrm{mL})$. IL-1 $\beta$ enhanced the expression of MMP-1 and MMP-3 mRNA in RASFs $(p<0.05)$, but not of TIMP-1 and TIMP-2 mRNA. EAAS inhibited the effects of IL-1 $\beta$ on the expression of MMP-1 and MMP-3 mRNA $(p<0.05$ and $p<0.01$, Figure 2$)$. IL-1 $\beta$ also enhanced the expression of COX-2 mRNA in RASFs $(p<0.01)$, but not of COX-1 (data not shown). EAAS inhibited
IL-1 $\beta$-induced expression of COX-2 mRNA $(p<0.05$, Figure 2).

\section{Effect of EAAS on IL-1 $\beta$-induced MMPs, TIMPs, and COX protein expressions in RASFs}

To further evaluate the expressions of MMPs, TIMPs, and COX proteins in mono-cultured RASFs, we performed Western blotting. RASFs were stimulated with IL-1 $\beta(1.0 \mathrm{ng} / \mathrm{mL})$ for 48 hours in the presence or absence of EAAS $(100 \mu \mathrm{g} / \mathrm{mL})$. IL- $1 \beta$ enhanced the expressions of MMP-1 and MMP-3 proteins in RASFs ( $\mathrm{p}<0.05)$, but not of TIMP-1 and TIMP-2 proteins, consistent with the results of mRNA expression (Figure 3). EAAS inhibited IL-1 $\beta$-induced expressions of MMP-1 and MMP-3 proteins $(\mathrm{p}<0.05$,). IL- $1 \beta$ also enhanced the expression of COX-2 protein in RASFs $(\mathrm{p}<0.01)$, but not of COX-1 (data not shown). EAAS inhibited IL$1 \beta$-induced expression of COX-2 protein ( $\mathrm{p}<0.05$ ). EAAS also significantly decreased expressions of MMP1, MMP-3, and COX-2 proteins compared to those in the dimethyl sulfoxide (DMSO) control condition without IL- $1 \beta$ and EAAS ( $\mathrm{p}<0.05)$.

\section{EAAS inhibits IL-1 $\beta$-induced PGE2 production in RASFs}

To confirm the effect of EAAS on the role of IL- $1 \beta$ in PGE2 production by RASFs, we examined the concentration of PGE2 in the culture supernatant. RASFs $(1 \times$ $10^{4}$ cells) were grown in $25 \mathrm{~cm}^{2}$ tissue-culture flasks for 48 hours before and after treatment with IL-1 $\beta$ (1.0 ng/ $\mathrm{mL})$ and/or EAAS $(100 \mu \mathrm{g} / \mathrm{mL})$. PGE2 production was increased after IL-1 $\beta$ treatment $(p<0.05)$ in comparison to the control, and it was significantly inhibited by treatment with EAAS at 48 hours, as was expected with the results of COX-2 expression (Figure 4).

\section{Effect of EAAS on IL-1 $\beta$-induced signal pathways in RASFs}

To demonstrate the involvement of the signal transduction and the mechanisms of the effects of EAAS on IL$1 \beta$-induced RASFs proliferation, MMPs and COX-2 expression, and PGE2 production, activation of MAPKs and NF- $\mathrm{kB}$ were evaluated in the RASFs. IL-1 $\beta$ activated the intracellular MAPKs, including extracellular signalregulated kinase (ERK), p-38, and c-Jun $\mathrm{N}$-terminal kinases (JNK), and EAAS significantly inhibited the IL$1 \beta$-induced intracellular MAPKs activation (Figure 5a). Activation of NF- $\mathrm{kB}$ and p65, and degradation of cytoplasmic IkBa was observed in RASFs treated with IL-1 $\beta$. These effects of IL-1 $\beta$ on NF- $\kappa B$ activation were abrogated by EAAS (Figure $5 \mathrm{~b}$ ). These results indicate that EAAS might inhibit IL- $1 \beta$-induced proliferation of RASFs, expression of COX-2, and production of PGE2 via intracellular MAPKs and NF- $\mathrm{KB}$ pathways. 
a

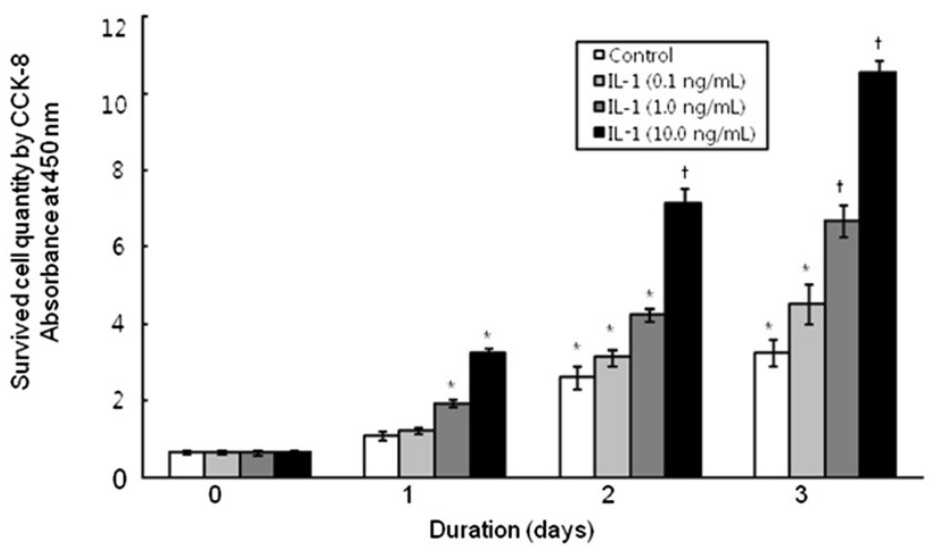

b

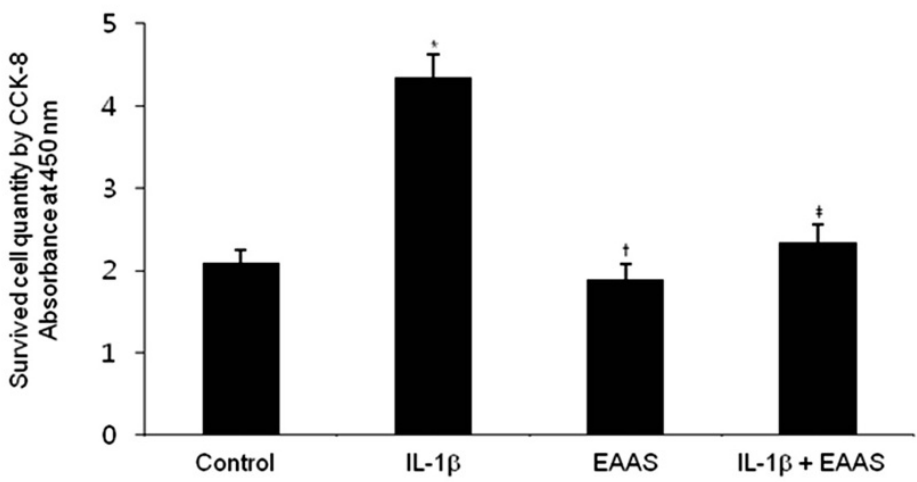

C

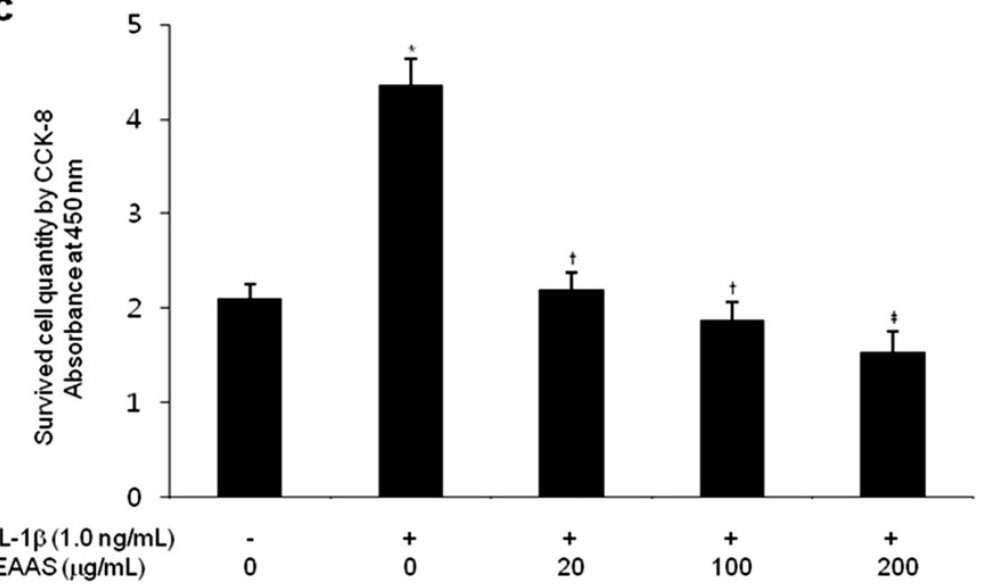

Figure 1 IL-1 $\beta$ increased the proliferation of RASFs dose-dependently and EAAS inhibits IL-1 $\beta$-induced proliferation of RASFs. IL-1 $\beta$ accelerated the proliferation of RASFs dose- and time-dependently (from 0.1 to $10 \mathrm{ng} / \mathrm{mL}$ ). Results are presented as mean $\pm S D, n=3$. ${ }^{*} p<0.05$ or $+p<0.01$ versus day 0 (a). EAAS $(100 \mu \mathrm{g} / \mathrm{mL})$ significantly inhibited IL-1-induced proliferation of RASFs after 2,3 days culture $(p<0.05)$ ${ }^{*} p<0.05$ versus no IL-1 $\beta$ and EAAS, $+p<0.05$ versus no IL-1 $\beta$ and EAAS, $\neq p<0.05$ versus IL-1 $\beta$ without EAAS (b). EAAS inhibited IL-1 $\beta$-induced proliferation of RASFs dose-dependently. ${ }^{*} p<0.05$ versus no IL-1 $\beta,+p<0.05, \neq p<0.01$ versus IL-1 $\beta$ without EAAS (c).

\section{Discussion}

Since herbal medicines have become popular around the world, pharmacological evidence to help understand the action of these medicines and their underlying mechanisms is needed. Recent therapeutic interest has focused on AS's cardiovascular, hepatoprotective, antioxidant, and immunomodulatory properties. The active principle of AS has been found to include a number of antiinflammatory substances [10]. The main chemical constituents of Angelica roots are ferulic acid, Z-ligustilide (the main lipophilic component of the essential oil of AS), angelicide, butylidenephthalide, and butylphthalide [11]. Ferulic acid has been demonstrated to exhibit antiAlzheimer's disease, antimicrobial, and anticarcinogenic 

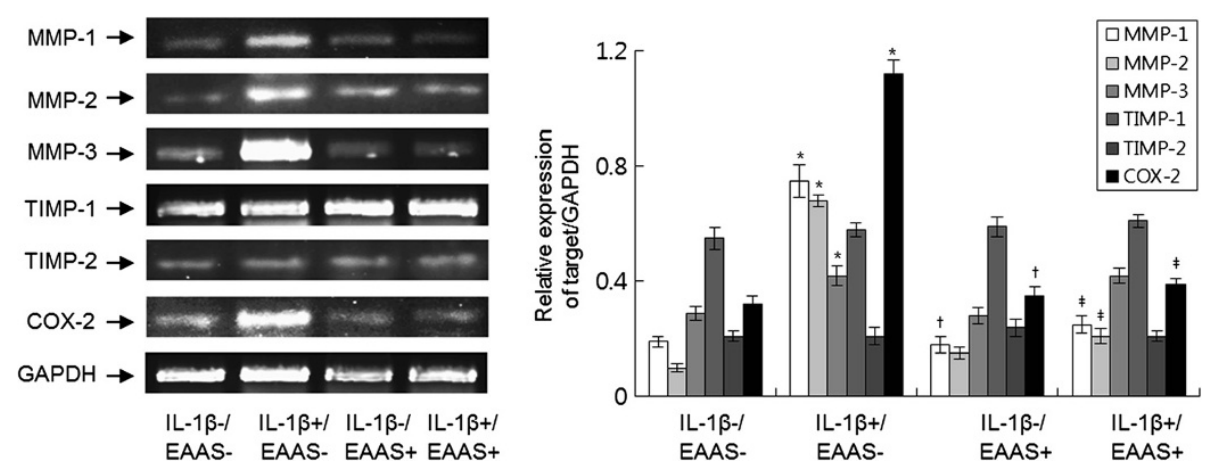

Figure 2 EAAS inhibited IL-1 $\beta$-induced production of MMPs and COX-2 in RASFs. IL-1 $\beta$ enhanced the expression of MMP-1, MMP -3 , TIMP-1, and COX-2 protein compared with the results without IL-1 $\beta$. EAAS inhibited the IL-1 $\beta$-induced expression of MMP-1, MMP-3, and COX-2 protein. Results are presented as mean \pm SD. $n=3 .{ }^{*} p<0.05$ versus no IL-1 $\beta$ and $E A A S,+p<0.05$ versus no IL-1 $\beta$ and EAAS, $\neq p<0.05$ versus IL-1 $\beta$ without EAAS.

properties. The amounts of ferulic acid and Z-ligustilide in the EAAS were calculated as 3.74 and $15.95 \mathrm{mg} / \mathrm{g}$ dry weight of the whole plant, respectively [9]. This component of EAAS also showed higher inhibitory activity of NF- $\mathrm{BB}$ transactivation than hexane or water fractions [9]. Furthermore, EAAS inhibits the production of inflammatory mediators alleviates acute inflammatory hazards and protect mice from endotoxic shock [12]. However, the exact components of AS that are involved in anti-inflammatory effects in RASFs are not yet known. Furthermore, there were no reports on the effects of EAAS on the inflammatory reactions, including production of MMPs, COX-2, and PGE2 by RASFs and the mechanisms, which play a crucial role in the pathogenesis of synovitis and articular destruction in RA. We showed here that EAAS inhibits IL-1 $\beta$-induced cell proliferation, COX-2 expression, and PGE2 production in RASFs by inhibition of activation of the MAP kinases ERK1/2, p-38, and JNK, and NF-kB signaling pathways. These findings suggest that EAAS can be used as a new therapeutic agent for management of RA by decreasing inflammation.

The hyperplasia of synovial fibroblasts is one of the most striking features of RA and is considered to be essential for the evolution of joint destruction in RA [2]. The tumor-like proliferation of RASFs is considered to be the major mechanism for the hyperplasic growth of the RA synovium and eventual destruction of the articular bones and cartilage. ${ }^{3}$ IL- $1 \beta$ plays an important role in the pathogenesis of inflammatory synovitis and joint destruction in RA by inducing the proliferation of fibroblast cell lines [13]. This study showed that EAAS significantly inhibits IL-1 $\beta$-induced proliferation of RASFs in a dose- and time-dependent manner. This probably means that EAAS would be an ideal treatment for RA. However, further study is required to know the effects of EAAS on RASF proliferation in the absence or presence of stimulating factors and to define the exact mechanism.
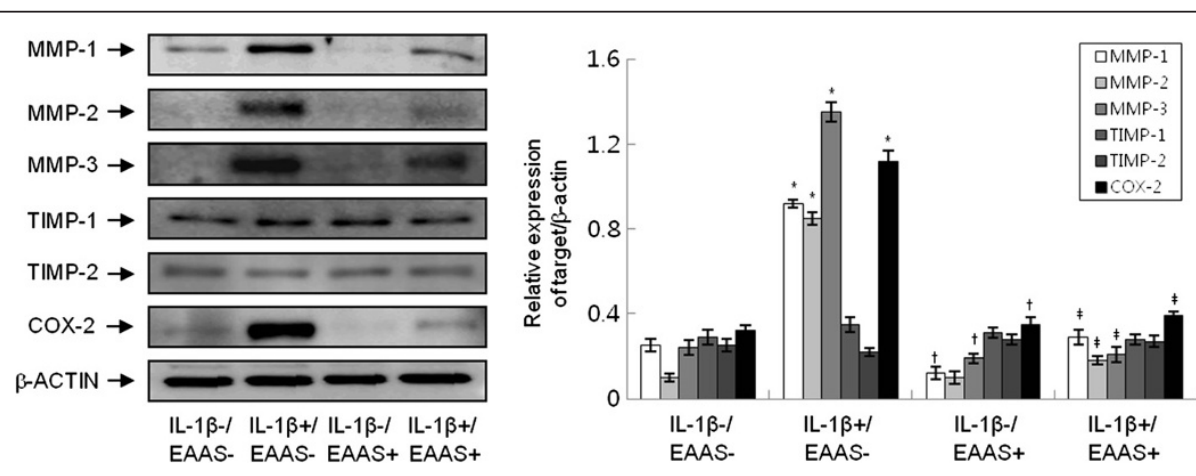

Figure 3 The protein were extracted from RASFs and analyzed by Western blotting. IL-1 $\beta$ enhanced the expression of MMP-1, MMP -3 , TIMP-1, and COX-2 protein compared with the results without IL-1 $\beta$. EAAS inhibited the IL-1 $\beta$-induced expression of MMP-1, MMP-3, and COX-2 protein. Results are presented as mean \pm SD. $n=3 .{ }^{*} p<0.05$ versus no IL-1 $\beta$ and EAAS, $+p<0.05$ versus no IL-1 $\beta$ and EAAS, $\neq p<0.05$ versus IL-1 $\beta$ without EAAS. 


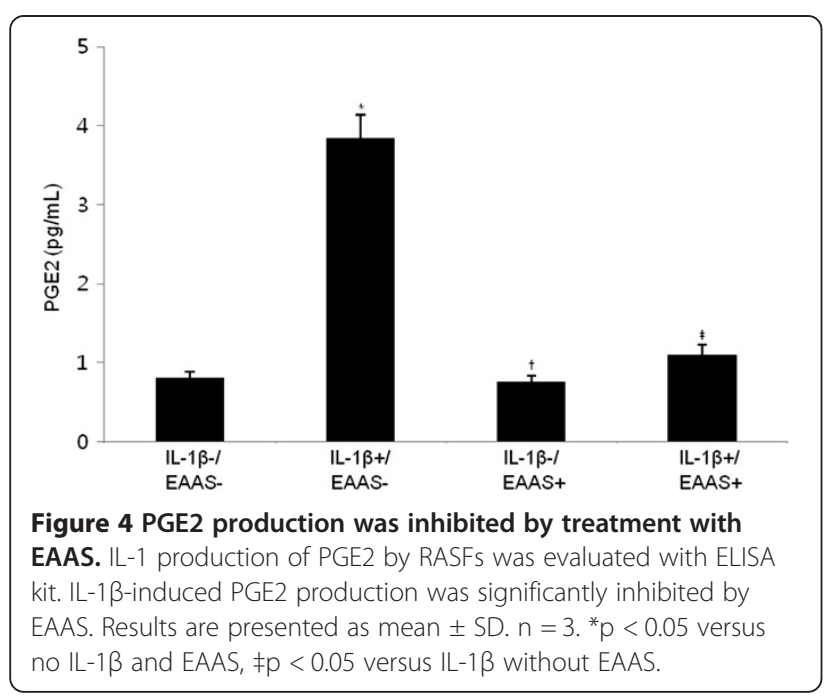

It has been well known that both COX-1 and COX-2 are expressed by human RASFs and that the expression of COX-2 is enhanced by proinflammatory cytokines, such as IL-1 $\beta$ [14]. COX-2 converts free arachidonic acid into prostaglandins, including a variety of bioactive products (PGI2, thromboxane A2 (TXA2), PGE2, and PGD2). PGE2, a pleiotropic mediator of inflammation, provides certain homeostatic functions, but its excessive production in the joints of RA patients is associated with many pathologic processes, and plays a critical role in eliciting the signs and symptoms of inflammation [15]. This study found that EAAS inhibits both IL-1 $\beta$-induced COX-2 protein expression and PGE2 synthesis dosedependently over time. Thus, further studies are also needed to identify the EAAS components that are responsible for the results of our study. It is also necessary to demonstrate the above effects on inflammatory joint disease with in vivo systems, such as animal models of RA and collagen-induced arthritis (CIA).

NF- $\mathrm{KB}$ and MAPKs participate in inflammation and destruction of joints in RA. It is known that inactive NF$\kappa B$ normally binds to IkB in the cytosol, and NF- $k B$ can be activated by proinflammatory cytokines, IL-1 $\beta$ and TNF- $\alpha$ [16]. JNK, p38, and ERK are expressed in cultured RASFs and are readily activated by IL-1 $\beta$ [17]. Prostaglandins have also been described as being under the influence of p38 MAPK [18]. This has been confirmed in a study in which it was reported that glucocorticoids destabilize COX-2 mRNA by inhibiting the p38 MAPK route [19]. Numerous studies have demonstrated that inhibitors of MAPKs or NF-kB decrease synovial inflammation, bone destruction, and cartilage damage in animal models of arthritis, including adjuvant arthritis in rats and CIA in mice [20]. To identify the mechanisms of the effects of EAAS on IL-1 $\beta$-induced proliferation of RASFs, expression of COX-2, and production of PGE2,
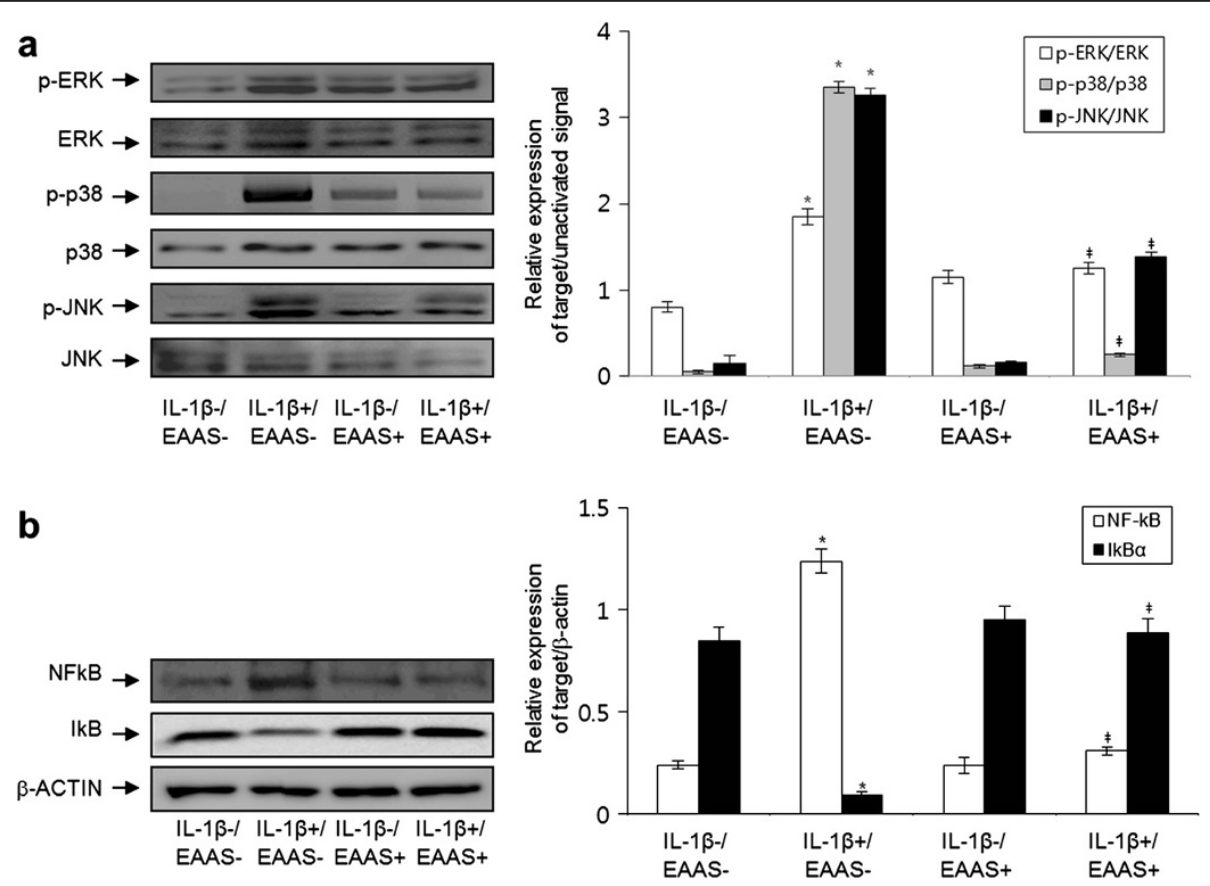

Figure 5 Effects of EAAS on IL-1 $\beta$-induced MAPK signal pathways and NF-kB activation in RASFs. IL-1 $\beta$ enhanced the phosphorylation of ERK, p38, and JNK and EAAS inhibited the IL-1 $\beta$-induced activation of p38 and JNK (a). IL-1 $\beta$ activated nuclear NF-kB and decreased cytoplasmic $\mathrm{IkBa}$ and EAAS inhibited the IL-1 $\beta$-induced activation of NF-kB (b). Results are presented as mean $\pm \mathrm{SD} . \mathrm{n}=3 .{ }^{*} \mathrm{p}<0.01$ versus no IL-1 $\beta$ and EAAS, $\neq \mathrm{p}<0.05$ versus $\mathrm{IL}-1 \beta$ without EAAS. 
the activation of the MAPKs and NF- $\mathrm{kB}$ was examined. This study showed that EAAS inhibits the IL-1 $\beta$ induced activation of NF- $\mathrm{kB}$ and phosphorylation of ERK, p38, and JNK. However, further studies are needed to identify the very important EAAS components and the mechanism by which EAAS inhibits the effects of IL- $1 \beta$ on RASFs. Further investigation is also needed to discern how EAAS suppresses NF- $\mathrm{KB}$ activation, and to identify the components of NF- $\mathrm{KB}$ that are suppressed and the kind of intracellular signaling factors specifically or directly involved in the effect of EAAS on the proliferation and PGE2 production in RASFs.

\section{Conclusions}

This is the first study to report that EAAS can inhibit the IL-1 $\beta$-induced proliferation of RASFs, expression of COX-2, and production of PGE2. This study also showed that EAAS inhibits the activation of NF-kB and phosphorylation of MAPKs pathways. Taken together, these findings suggest that EAAS may be useful in the treatment of inflammatory diseases, including RA. However, further studies are required to identify the exact mechanism underlying the inhibition of synovial cell proliferation and inflammatory reactions, and to find the active components in the EAAS.

\section{Methods}

\section{Preparation of crude extract of Angelica sinensis}

AS was collected from Jiri Mountain in South Korea and plant material was identified by an authority at the Rheumatology Laboratory and Research Center for Pulmonary Diseases, Chonbuk National University Medical School, Jeonju, Jeonbuk, South Korea. In total, $10 \mathrm{~g}$ of AS was extracted with $300 \mathrm{ml}$ of $95 \%$ ethanol at $50^{\circ} \mathrm{C}$ for 3 hours twice. The total crude extract was evaporated under vacuum to yield a residue, and then the residue was suspended in $90 \%$ ethanol and successively partitioned with hexane, benzene, trichloromethane, ethyl acetate, n-butanol and water fractions, consecutively as described [21]. The ethyl acetate fraction was used in this study after well drying the fraction. And we used kaempferol $0.852 \mathrm{ug}$ and decursin $2.116 \mathrm{ug}$ in $1 \mathrm{mg} / \mathrm{mL}$ of extract by quantifying the content.

\section{Reagents and antibodies}

Recombinant human IL-1 $\beta$ was purchased from R\&D system (Minneapolis, Minnesota, USA). Monoclonal antibody (mAb) against MMP-1, MMP-3, tissue inhibitor of metalloproteinase (TIMP), and COX-2 was purchased from Santa Cruz Biotechnology (Santa Cruz, CA, USA). mAb against extracellular signal-regulated kinase (ERK), phosphorylated ERK (p-ERK), C-jun N-terminal kinase (JNK), phosphorylated JNK (p-JNK), p38, p-p38, nuclear factor $\kappa \mathrm{B}(\mathrm{NF}-\mathrm{kB})(\mathrm{p} 65)$, nuclear factor of kappa light polypeptide gene enhancer in B-cells inhibitor, alpha $(\mathrm{I} \kappa \mathrm{B} \alpha)$ and $\beta$-actin were purchased from Cell Signaling (Beverly, MD, USA). Fetal bovine serum (FBS) was obtained from Gibco BRL (Life Technologies, Grand Island, NY, USA).

\section{Isolation and culture of RASFs}

Synovial tissues obtained at the time of total knee arthroplasty in patients who fulfilled the American College of Rheumatology Criteria for RA [22], as previously described [23]. Synovial fibroblasts from passages 3-7 were used for each experiment and were morphologically homogeneous and had the appearance of RASFs with typical fibroblastoid configuration under inverse microscopy. The purity of the cells was tested by flow cytometry using phycoerythrin (PE)-conjugated anti-Thy-1 (CD90) or antiCD14 and fluorescein isothiocyanate (FITC)-conjugated anti-CD3 mAb (BD Pharmingen, San Diego, CA). Informed consent was obtained from all patients, and the study protocol was approved by the Chonbuk National University Hospital Ethical Committee.

\section{RNA Isolation and semiquantitative RT-PCR of COX, MMPs and TIMP}

Total RNA was extracted from cultured cells using the TRIsol reagent (Invitrogen, Carlsbad, CA, USA) following the manufacturer's instructions. One microgram of RNA was reverse-transcribed using Maxime RT Premix Kit (iNtRON Biotechnology, Korea). cDNA was amplified using the following primer sets: COX-1 (sense) $5^{\prime}$-GCT ATT CCG GCC CCA ACT-3' (antisense) 5'-GAT GAA GGT GGC ATT GAC AAA CT-3', COX-2 (sense) 5' TCC TTG CTG TTC CCA CCC ATG-3' (antisense) 5' CAT CAT CAG ACC AGG CAC CAG-3', MMP-1 (sense) 5'-GAA GGA GAT GAA GCA GCC CAG ATG T-3' (antisense) 5'-CAG TTG TGG CCA GAA AAC AGA AGT GAA A-3', MMP-3 (sense) 5' GAC ACC AGC ATG AAC CTT GTT-3' (antisense) 5'-GGA ACC GAG TCA GGA CTA TG-3', TIMP-1 (sense) 5'-CCT TCT GCA ATT CCG ACC TCG TC-3' (antisense) 5'-CGG GCA GGA TTC AGG CTA TCT GG-3', glyceraldehyde 3-phosphate dehydrogenase (GAPDH) (sense) 5'-ACC ACA GTC CAT GCC ATC AC-3' (antisense) 5'-TCC ACC ACC CTG TTG CTG TA-3'. PCR products were electrophoresed by using $1 \%$ agarose gels and visualized by staining with ethidium bromide. Densitometric analysis was performed on the relative intensity of each band using the Multi Gauge program, version 3.0 (Fuji film, Tokyo, Japan).

\section{Cell viability analysis}

Cell viability was determined by a cell counting kit- 8 (CCK-8; Dojindo Laboratories, Japan) according to the manufacturer's instructions. Briefly, 2-(2-methoxy-4- 
nitrophenyl)-3-(4-nitropenyl)-5-(2,4-disulfophenyl)-2Htetrazolium (CCK-8) was reduced by dehydrogenases in cells to yield an orange-colored product (formazan) [24]. The amount of the formazan dye generated by dehydrogenases in cells was directly proportional to the number of living cells. RASFs $\left(1 \times 10^{5}\right.$ cells per well in complete RPMI-1640 media in a 96-well plate) were cultured in $200 \mathrm{~mL}$ medium per well without antigen stimulation in the presence or absence of $100 \mu \mathrm{g} / \mathrm{mL}$ EAAS for 2 days. CCK-8 $(20 \mathrm{~mL})$ was added to each well of the plate and the cells were incubated for 2-3 hours. The absorbance was measured at $450 \mathrm{~nm}$ using a microplate reader.

\section{Assay of PGE2 production}

RASFs were grown in $25 \mathrm{~cm}^{2}$ tissue-culture flasks for 48 hours before treatment. After washing with PBS (pH 7.4), cells were pretreated with IL-1 $\beta(1.0 \mathrm{ng} / \mathrm{mL})$ or EAAS $(100 \mu \mathrm{g} . \mathrm{mL})$ at $37^{\circ} \mathrm{C}$ for 48 hours in DMEM containing $10 \%(\mathrm{v} / \mathrm{v}) \mathrm{FCS}$ in an atmosphere of $5 \% \mathrm{CO}_{2}$. The culture supernatant described above was collected at 2 days. The level of PGE2 in the medium was determined by ELISA kit (R\&D Systems) in accordance with the instructions of the manufacturer.

\section{Immunoblotting}

RASFs $\left(1 \times 10^{6}\right.$ cells $)$ were seeded on $100-\mathrm{mm}$ culture dishes and harvested in phosphate buffered saline (PBS) after stimulation as described above. Cells were lysed in lysis buffer containing $50 \mathrm{mM}$ Tris-CL, $150 \mathrm{mM} \mathrm{NaCl}$, 5 mM EDTA 1\% Triton X-100, $1 \mathrm{mM}$ sodium fluoride, $1 \mathrm{mM}$ sodium vanadate, $1 \%$ deoxycholate, and protease inhibitors. To determine the membrane COX-2 expression on RASFs, cell membranes were prepared from isolated RASFs, as described previously [25]. To analyze NF-kB (p65), nuclear extract was prepared using a previously described method [23]. To determine the cytoplasmic IkBa, cytoplasmic extracts were prepared from isolated RASFs as described previously [23]. The protein concentration was determined by the Bio-Rad protein assay regent (Bio-Rad Laboratories, USA). Samples (50 mg) were prepared with the four volume of $0.5 \mathrm{M}$ Tris buffer (pH 6.8) containing 4\% SDS, $20 \%$ glycerol and $0.05 \%$ bromophenol blue at $95^{\circ} \mathrm{C}$ for $5 \mathrm{~min}$. SDS-PAGE was performed in $10 \%$ slab gel. Proteins were transferred to nitrocellulose paper. The membrane was washed in blocking buffer $(10 \mathrm{mM}$ Tris- $\mathrm{HCl} \mathrm{pH} 8.0,150 \mathrm{mM}$ $\mathrm{NaCl}, 5 \%$ fat-free milk) for $60 \mathrm{~min}$ at room temperature with shaking and then washed with TBST (TBS, 0.01\% Tween 20). Primary antibodies $(10 \mathrm{mg} / \mathrm{ml})$ against MMP-1, -3, TIMP-1, -2, COX-1, -2, ERK, p-ERK-1/2, p-38, p-p38 MAPK, JNK, p-JNK, NF-kB (p65), IkBa and $\beta$-actin was incubated at $4^{\circ} \mathrm{C}$ for $4 \mathrm{hr}$. The secondary HRP-conjugated antibody was goat anti-mouse $\operatorname{IgG}$
(Stressgen Bioreagents, Ann Arbor, MI, USA). Reactive proteins were detected using enhanced chemiluminescence (ECL, Amersham Life Sciences, Arlington, IL, USA) using Fuji film LAS-3000 (Tokyo, Japan).

\section{Statistical analysis}

All data were expressed as the mean \pm SD of triplicates and all data were analyzed by the SPSS 18.0 program. Group mean values were compared by Student's t test or ANOVA as appropriate. The significance of difference was defined as $p$ values $<0.05$, or $p$ values $<0.01$.

\section{Competing interests}

The authors declare that they have no competing interest.

\section{Authors' contributions}

YWH \& LWS- supervised the research project. SMS \& LEG \& LWS- Coordinated \& management of research activities. LJH \& OYJ- Draft the manuscript. All authors read and approved the final manuscript.

Received: 18 February 2014 Accepted: 11 August 2014

Published: 5 September 2014

\section{References}

1. Pope RM: Apoptosis as a therapeutic tool in rheumatoid arthritis. Nat Rev Immunol 2002, 2:527-535.

2. Han MK, Kim JS, Park BH, Kim JR, Hwang BY, Lee HY, Song EK, Yoo WH: NF-kappaB-dependent lymphocyte hyperadhesiveness to synovial fibroblasts by hypoxia and reoxygenation: potential role in rheumatoid arthritis. J Leukoc Biol 2003, 73:525-529.

3. Choy EH, Panayi GS: Cytokine pathways and joint inflammation in rheumatoid arthritis. N Engl J Med 2001, 344:907-916.

4. Kim SH, Lee SE, Oh H, Kim SR, Yee ST, Yu YB, Byun MW, Jo SK: The radioprotective effects of bu-zhong-yi-qi-tang: a prescription of traditional Chinese medicine. Am J Chin Med 2002, 30:127-137.

5. Wang X, Weo I, Ouyang JP, Muller S, Gentils M, Vauchois G, STOLTZ: Effects of an angelica extract on human erythrocyte aggregation, deformation and osmotic fragility. Clin Hemorheol Microcirc 2001, 24:201-205.

6. Xie F, Li X, Sun K, Chu Y, Cao H, Chen N, Wang W, Liu M, Liu W, MAO: An experimental study on drugs for improving blood circulation and removing blood stasis in treating mild chronic hepatic damage. J Tradit Chin Med 2001, 21:225-231.

7. Ye YN, Liu ES, Shin WY, Koo MW, Li Y, Wei EQ, Matsui H, Cho CH: A mechanistic study of proliferation induced by Angelica sinensis in a normal gastric epithelial cell line. Biochem Pharmacol 2001, 61:1439-1448.

8. Ye YN, Liu ES, Li Y, So HL, Cho CC, Sheng HP, Lee SS, CHO: Protective effect of polysaccharides-enriched fraction from Angelica sinensis on hepatic injury. Life Sci 2001, 69:637-646.

9. Chao WW, Kuo YH, Li WC, Lin BF: The production of nitric oxide and prostaglandin E2 in peritoneal macrophages is inhibited by Andrographis paniculata, Angelica sinensis and Morus alba ethyl acetate fractions. J Ethnopharmacol 2009, 122:68-75.

10. Yan JJ, Cho JY, Kim HS, Kim KL, Jung JS, Juh SO, Suh HW, Kim YH, Song DK: Protection against beta-amyloid peptide toxicity in vivo with long-term administration of ferulic acid. Br J Pharmacol 2001, 133:89-96.

11. Zhao KJ, Dong TT, Tu PH, Song ZH, Lo CK, Tsim KW: Molecular genetic and chemical assessment of radix Angelica (Danggui) in China. J Agric Food Chem 2003, 51:2576-2583.

12. Chao WW, Hong YH, Chen ML, Lin BF: Inhibitory effects of Angelica sinensis ethyl acetate extract and major compounds on NF-kappaB trans-activity and LPS-induced inflammation. J Ethnopharmacol 2010, 129:244-249.

13. Gitter BD, Labus JM, Lees SL, Scheetz ME: Characteristics of human synovial fibroblast activation by IL-1 beta and TNF alpha. Immunology 1989, 66:196-200.

14. Crofford L, Wilder RL, Ristimaki AP, Sano H, Remmers EF, Epps HR, Hla T: Cyclooxygenase-1 and -2 expression in rheumatoid synovial tissues. 
Effects of interleukin-1 beta, phorbol ester, and corticosteroids. J Clin Invest 1994, 93:1095-1101.

15. Martel-Pelletier J, Pelletier JP, Fahmi H: New insights into prostaglandin biology. J Rheumatol 2004, 31:14-16.

16. Verma IM, Stevenson JK, Schwarz EM, Van Antwerp D, Miyamoto S: Rel/NF-kappa B/I kappa B family: intimate tales of association and dissociation. Genes Dev 1995, 9:2723-2735.

17. Han Z, Boyle DL, Chang L, Bennett B, Karin M, Yang L, Manning AM, Firestein GS: c-Jun $\mathrm{N}$-terminal kinase is required for metalloproteinase expression and joint destruction in inflammatory arthritis. J Clin Invest 2001, 108:73-81.

18. Guan Z, Baier LD, Morrison AR: p38 mitogen-activated protein kinase down-regulates nitric oxide and up-regulates prostaglandin E2 biosynthesis stimulated by interleukin-1 beta. J Biol Chem 1997, 272:8083-8089.

19. Lasa M, Brook M, Saklatvala J, Clark AR: Dexamethasone destabilizes cyclooxygenase 2 mRNA by inhibiting mitogen-activated protein kinase p38. Mol Cell Biol 2001, 21:771-780.

20. Mcintyre KW, Shuster DJ, Gillooly KM, Dambach DM, Pattoli MA, Lu P, Zhou XD, Qiu Y, Zusi FC, Burke JR: A highly selective inhibitor of I kappa B kinase, BMS-345541, blocks both joint inflammation and destruction in collagen-induced arthritis in mice. Arthritis Rheum 2003, 48:2652-2659.

21. Seo WG, Pae HO, Oh GS, Chai KY, Yun YG, Chung HT, Jang KK, Kwon TO: Ethyl acetate extract of the stem bark of Cudrania tricuspidata induces apoptosis in human leukemia HL-60 cells. Am J Chin Med 2001, 29:313-320.

22. Arnett FC, Edworthy SM, Bloch DA, Mcshane DJ, Fries JF, Cooper NS, Healey LA, Kaplan SR, Liang MH, Luthra HS: The American Rheumatism Association 1987 revised criteria for the classification of rheumatoid arthritis. Arthritis Rheum 1998, 31:315-324.

23. Lee HY, Jeon HS, Song EK, Han MK, Park SI, Lee SI, Yun HJ, Kim JR, Kim JS, Lee YC, Kim SI, Kim HR, Choi JY, Kang I, Kim HY, Yoo WH: CD40 ligation of rheumatoid synovial fibroblasts regulates RANKL-mediated osteoclastogenesis: evidence of NF-kappaB-dependent, CD40-mediated bone destruction in rheumatoid arthritis. Arthritis Rheum 2006, 54:1747-1758.

24. Hodgkin PD, Yamashita LC, Coffman RL, Kehry MR: Separation of events mediating $B$ cell proliferation and Ig production by using $T$ cell membranes and lymphokines. J Immunol 1990, 145:2025-2034.

25. Nakagawa T, Takahashi M, Ozaki T, Watanabe KK, Todo S, Mizuguchi H, Hayakawa T, Nakagawara A: Autoinhibitory regulation of $p 73$ by Delta Np73 to modulate cell survival and death through a p73-specific target element within the Delta Np73 promoter. Mol Cell Biol 2002, 22:2575-2585.

doi:10.1186/0717-6287-47-41

Cite this article as: Lee et al.: Ethyl acetate fraction from Angelica sinensis inhibits IL-1 $\beta$-induced rheumatoid synovial fibroblast proliferation and COX-2, PGE2, and MMPs production. Biological Research 2014 47:41.

\section{Submit your next manuscript to BioMed Central and take full advantage of:}

- Convenient online submission

- Thorough peer review

- No space constraints or color figure charges

- Immediate publication on acceptance

- Inclusion in PubMed, CAS, Scopus and Google Scholar

- Research which is freely available for redistribution 